\title{
OPEN Eco friendly silver nanoparticles synthesis by Brassica oleracea and its antibacterial, anticancer and antioxidant properties
}

\author{
Sabah Ansar ${ }^{1 凶}$, Hajera Tabassum ${ }^{1}$, Norah S. M. Aladwann ${ }^{1}$, Mir Naiman Ali $^{2}$, \\ Basmah Almaarik ${ }^{1}$, Salma AlMahrouqi ${ }^{3}$, Manal Abudawood ${ }^{4}$, Naheed Banu ${ }^{5}$ \& Roua Alsubki ${ }^{4}$
}

Production of environmentally amenable silver nanoparticles (AgNPs) has garnered the interest of the scientific community owing to their broad application primarily in the field of optronics, sensing and extensively in pharmaceuticals as promising antioxidant, antimicrobial and anticancer agents. The current study emphases on production of ecofriendly silver nanoparticles from Brassica oleracea (BO) and investigated their antibacterial, anticancer and antioxidant activity. The characteristics of synthesized BO-AgNPs were studied by ultraviolet-visible spectroscopy, particle size analysis, electro kinetic/zeta potential analysis, and Transmission electron microscope (TEM). A distinctive absorption maximum at $400 \mathrm{~nm}$ confirmed the formation of BO-AgNPs and data on TEM analysis have shown that the synthesized nanoparticles were predominantly spherical in shape. The BO-AgNPs obtained were assessed for antibacterial, antioxidant, and cytotoxic ability in MCF-7 cells. The antibacterial activity expressed was maximum against Staphylococcus epidermidis (Gram positive) and Pseudomonas aeruginosa (Gram negative) with DIZ of $14.33 \pm 0.57$ and $12.0 \pm 0.20 \mathrm{~mm}$ respectively. Furthermore, the ability of the synthesized green nanoparticles to scavenge free radicals revealed a strong antioxidant activity. The cytotoxicity increased proportionately with increasing concentration of the green synthesized BO-AgNPs with maximum effect at $100 \mu \mathrm{g} / \mathrm{ml}$ and IC50 of $55 \mu \mathrm{g} / \mathrm{ml}$. In conclusion, the data obtained in the study is reflective of the role of BO-AgNPs as potential and promising antimicrobial agent against bacterial infections and potential anticancer agent in cancer therapy.

Nanoscience is one of the remarkable fields of science dealing with utilization and development of structures and materials with size ranging in nanometer scale. Nanoparticles (NPs) are nano-sized ranging from 1-100 nm produced through numerous methods. There are various methods for synthesis of NPs, yet these methods employ hazardous and toxic chemicals, which poses a high risk of toxicity. Other disadvantages related to these methods, is low production rate and low biodegradability ${ }^{1-3}$. The production of NPs employing nontoxic conditions is critical to address the increasing concerns regarding their toxicity ${ }^{4}$. The green chemistry utilizing plant as source for production of AgNPs is gaining importance. The usage of plants for the manufacture of NPs has gathered the interest of scientists as a quick, economical, and environmentally sustainable method ${ }^{5,6}$. The reduction potential of the plant is crucial in formation of nanoparticles, mediating the stabilization and reduction and their capping. Green synthesis of NPs involves three phases. In phase I, mineral ions are eluted from salts in the manifestation of plant products as reducing agents with subsequent reduction of mineral ions from bi-valent to zerovalent forms (activation phase). In the second phase (growth phase) NPs formed by the coalescence of isolated metal atoms in their reduced form undergo biological reduction. Eventually, NPs get capped by plant metabolites during the termination phase and ones with a stable morphology are procured ${ }^{7-9}$.

Biological synthesis of nanoparticles mediated through plants and microorganisms has been procured as excellent antimicrobials. A range of microbial species used for Ag-NP synthesis is safe, biocompatible and

\footnotetext{
${ }^{1}$ Department of Clinical Laboratory Sciences, College of Applied Medical Sciences, King Saud University, P.O. Box 10219, Riyadh 11433, Saudi Arabia. ${ }^{2}$ Microbiology Section, Riyadh Municipality Central Area Labs, Riyadh, Saudi Arabia. ${ }^{3}$ Department of Nutrition and Dietetics, Sultan Qaboos University Hospital, Seeb, Oman. ${ }^{4}$ Chair of Medical and Molecular Genetics Research, Department of Clinical Laboratory Sciences, College of Applied Medical Sciences, King Saud University, Riyadh, Saudi Arabia. ${ }^{5}$ Department of Physical Therapy, College of Medical Rehabilitation, Qassim University, Buraydah, Saudi Arabia. ${ }^{\circledR}$ email: sabahansar16@gmail.com
} 


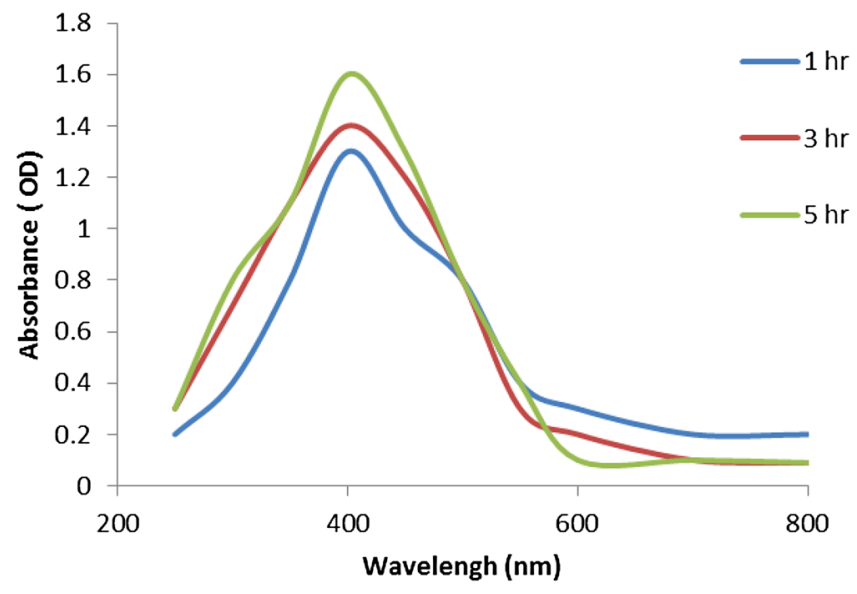

Figure 1. Absorption spectra of the synthesized Ag nanoparticles from B. oleracea leaf aqueous extract.

ecofriendly ${ }^{10-14}$. Green synthesis of nanoparticles from endophytic actinomycetes and Penicillium have also gained importance in nanoscience research ${ }^{15}$. Owing to increased antibiotic resistance to microorganisms, new antimicrobials that can reduce healthcare costs are in demand. There has been increase in requirement for these new antimicrobials at higher rates owing to its use in varying fields like medicine, environment, textiles, and cosmetics. They are primarily prepared from noble metals, e.g., silver, gold, platinum, and palladium with AgNPs being the most exploited ${ }^{16}$. Apart from the varied role of nanoparticles in the field of nanotechnology including the chemical kinetics, nanoelectronics, cytocompatibility studies, tissue engineering and targeted drug delivery, the applications are extended to production of potential antimicrobial and anticancer agents in the field of biomedical sciences ${ }^{17-20}$. Interestingly, nanotechnology with the distinctive characteristics of metal nanoparticles like high surface-to-volume ratio, ease of synthesis and surface functionalization makes prospectives in cancer therapeutics ${ }^{21,22}$.

Brassica oleracea, is a popular cruciferous vegetable belonging to the family Brassicaceae is considered a food of high nutritional value. It possess effective biological and immunological activities and is very good source of electrolytes, minerals, vitamins, dietary fibers, anti-oxidant compound (sulforaphane, flavonoids etc.) and phytochemicals like indoles which possess detoxifying property ${ }^{23,24}$. Nevertheless, nanoparticles synthesized from Brassica species have been reported earlier ${ }^{25-30}$, a comparative analysis of different Brassicaceae members for their reducing capacity, for controlled synthesis of AgNPs and to explore better performing varieties with higher antimicrobial potential is lacking. Hence, in the present study owing to the presence of antioxidants and other detoxifying chemicals, the NPs synthesized from $B$. oleracea has been hypothesized to play role as an effective antimicrobial and anticancer tools. Moreover, the production of AgNPs mediated from B. oleracea need to be evaluated for antimicrobial screening, anticancer and antioxidant properties to provide a green alternative to other chemically synthesized AgNPs. The study thus aimed to produce silver nanoparticles from $B$. oleracea leaves by green chemistry process, an alternative ecofriendly approach for its potential applications.

\section{Results}

In this study, AgNPs production was completed by treating extract of BO leaves with silver nitrate solution. This reaction showed the color change from pale green to dark brown. A persistent $\lambda \max$ (at $400 \mathrm{~nm}$ ) shown at altered time intervals reflects of the contained molecular size and configuration of the synthesized NPs (Fig. 1). This complex was responsible for changing color from greenish yellow to brown. This color change indicates the formation of $\mathrm{Ag}$ nanoparticles. The Ag nanoparticles synthesized in each extract solution was analyzed using UV-Vis spectroscopy. Reduction of Ag ions using BO-leaf extract is confirmed by the UV spectrum which exhibited a strong absorption peak at $\sim 415 \mathrm{~nm}$, which ultimately confirmed the formation of BO-AgNPs.

Results of TEM image (Fig. 2) showed that the highly-densed AgNPs formed by the BO leaves further affirm the development of silver nanostructure. The images clearly show the formation of relatively spherical nanoparticles with average diameter of $20 \mathrm{~nm}$, with relatively homogenous distribution.

The present study recorded a particle size of BO-AgNPs in ZS analysis as shown in Fig. 3. As a result of high sensitivity of ZS, nanoparticles showed slightly large size due to aggregation. Figure 4 depicts the EDX spectrum, revealing the clear elemental composition profile of the green synthesized BO-AgNPs. The EDX profile demonstrated a remarkable defined silver peak along with distinguishable prominent oxygen, chloride, and potassium signals. Notably, the intense signal at $3 \mathrm{keV}$ strongly confirms that the major element was silver. The other signals in the range of $0.0-0.5 \mathrm{keV}$ represent the typical absorption of oxygen, chlorine and potassium and thus indicates the presence of the plant extract (as a capping ligand) on the surfaces of the NPs that tends to bound AgNPs surface during extraction. Figure 5 depicts the FTIR profile, with strong absorption peaks for O-H groups of phenols and $\mathrm{C}-\mathrm{H}$ aromatic stretch of groups at $\sim 3500 \mathrm{~cm}^{-1}$ and $1600 \mathrm{~cm}^{-1}$ respectively.

The synthesized BO-AgNPs were evaluated for antibacterial activities towards Gram-positive and Gramnegative bacterial strains by the inhibition zones and MIC. About nine varied strains of bacteria were used for the antibacterial efficiency of the synthesized BO-AgNPs as shown in Fig. 6. Results of disc diffusion assay expressed 


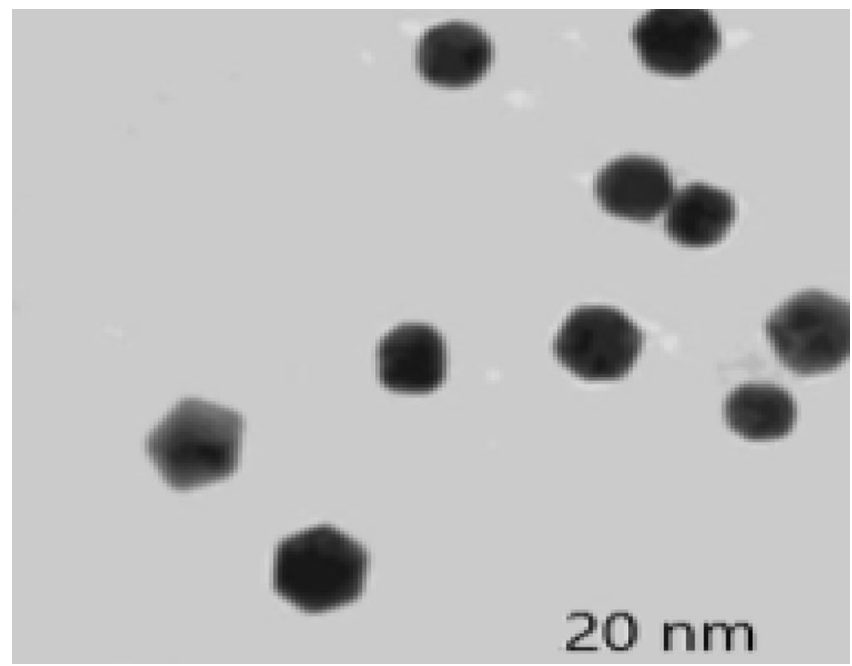

Figure 2. TEM image of Ag nanoparticles prepared with aqueous B. oleracea leaf extract.

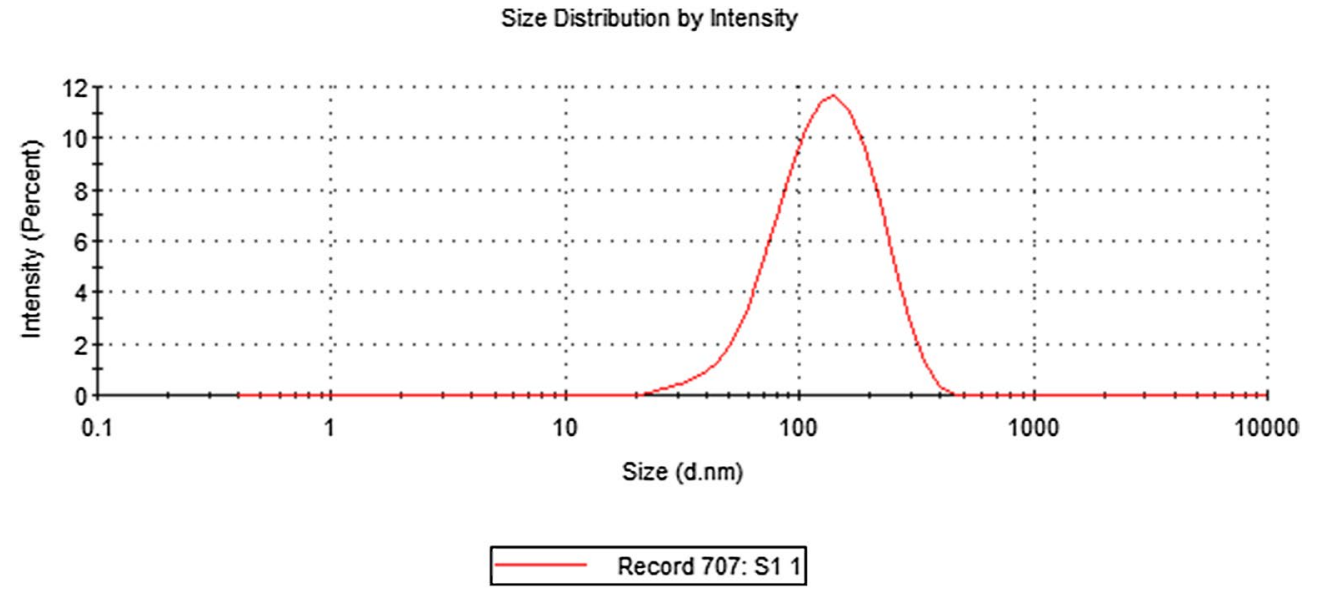

Figure 3. Average size of Ag nanoparticles prepared with aqueous B. oleracea leaf extract.

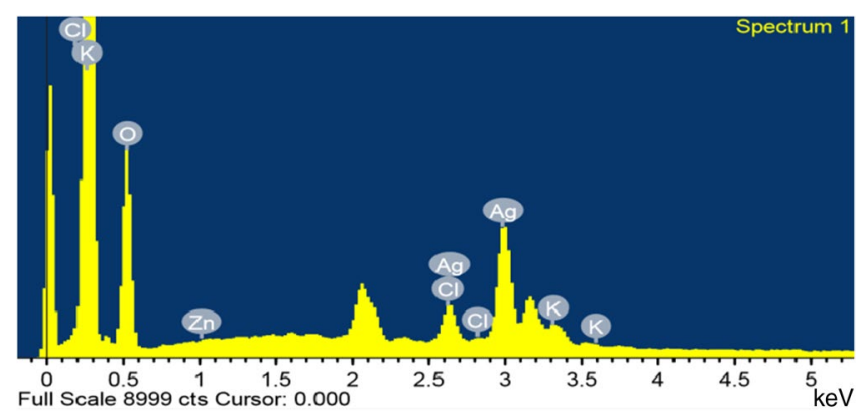

Figure 4. Energy dispersive X-ray elemental analysis of Ag nanoparticles prepared with aqueous B. oleracea leaf extract.

as diameter of inhibition zone (DIZ) (Table 1). Minimum inhibitory concentration was also determined for synthesized nanoparticles and the results are shown in Table 2.

The cytotoxicity of synthesized AgNPs was observed following reduction of 3-(4,5-dimethylthiazol-2-yl)2,5-diphenyl tetrazolium bromide dye (MTT). Post 24-h treatment of MCF-7 cells with BO-AgNPs, revealed that the viability of cells is dependent on the dosage of biosynthesized AgNPs thus reflecting the antagonistic effect 


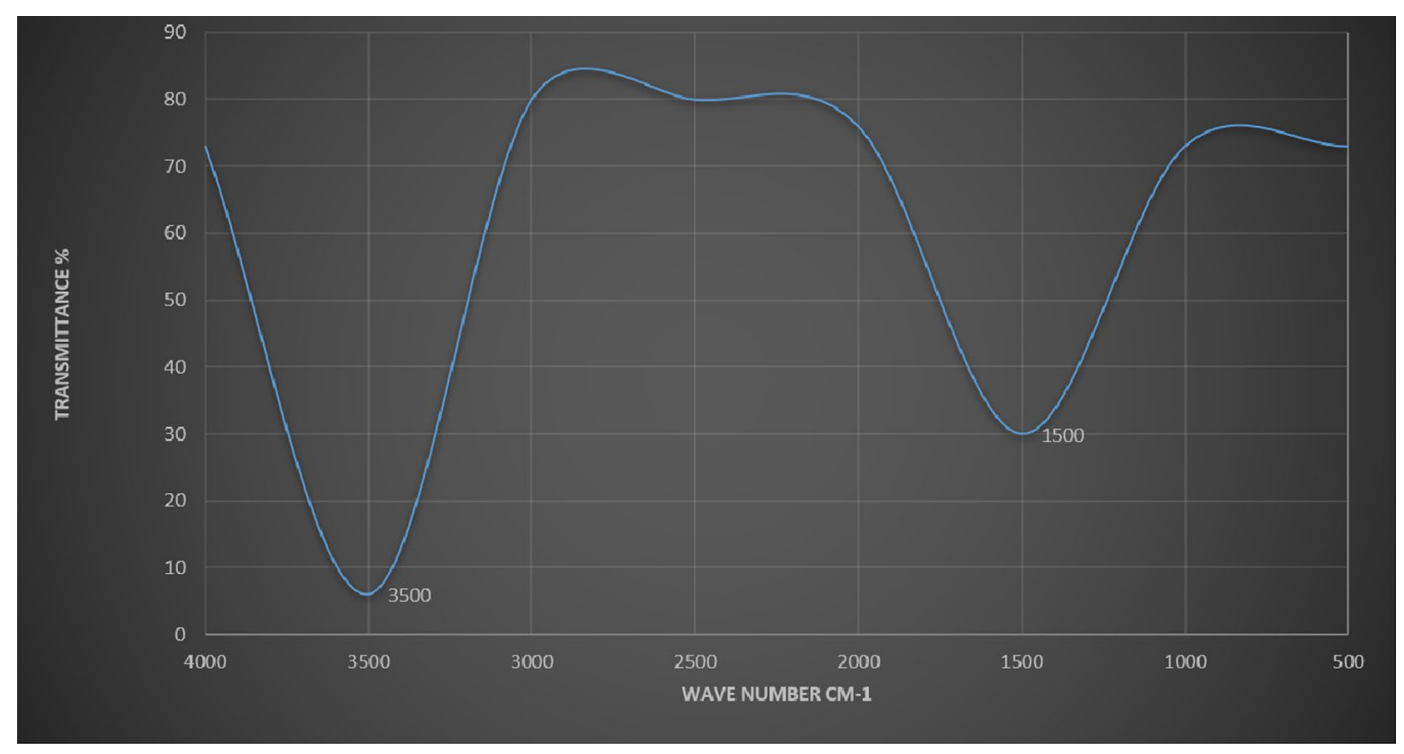

Figure 5. FT-IR analysis of Ag nanoparticles prepared with aqueous B. oleracea leaf extract.

upon the cancer cell line. MCF-7 cells treated with B. oleracea capped silver nanoparticles, exhibited cell death at higher concentrations as shown in Fig. 7. Each result represents the mean viability \pm standard deviation (SD). Cell viability was calculated as the percentage of viable cells compared to untreated controls. It was observed that the cytotoxicity increased proportionately with increasing concentration of the green synthesized BO-AgNPs with maximum effect at $100 \mu \mathrm{g} / \mathrm{ml}$ with IC-50 of $55 \mu \mathrm{g} / \mathrm{ml}$.

Antioxidant activity of BO-AgNPs. The antioxidant activity of the green synthesized BO-AgNPs was evaluated using DPPH, nitric oxide, superoxide and hydroxyl radical and are depicted in Fig. 8a-d. The DPPH scavenging activity of BO-AgNPs using ascorbic acid as standard antioxidant is shown in Fig. 8a. As reflected from the figure, the antioxidant properties of the samples increased with increasing concentrations of BOAgNPs in the range $50-200 \mu \mathrm{g} / \mathrm{ml}$ resulting in increase in percentage DPPH radical scavenging abilities. A dose dependent pattern was observed in the scavenging activity, which increased with increase in dose of the BOAgNPs. Nevertheless, the scavenging potential of the BO-AgNPs was comparatively lower than that of the standard. A concentration of $200 \mu \mathrm{g} / \mathrm{ml}$ for BO-AgNPs exhibited the highest antioxidant activity (79\%). Furthermore, the IC 50 value of BO-AgNPs around $50.37 \mu \mathrm{g} / \mathrm{ml}$ comparable with IC50 value of ascorbic acid $44.10 \mu \mathrm{g} / \mathrm{ml}$ demonstrated the potential radical scavenger properties of BO-AgNPs. Also, antioxidant activity by nitric oxide assay was found effective in range of $50-81 \%$ for the above-mentioned concentrations (Fig. $8 \mathrm{~b}$ ). The superoxide radical and hydroxyl scavenging activity of $\mathrm{BO}-\mathrm{AgNPs}$ were recorded around $70 \%$ and $35-71 \%$ respectively at a higher concentration of $200 \mu \mathrm{g} / \mathrm{ml}$ as depicted in Fig. 8c,d. As evident from the above scavenging experiments, the synthesized nanoparticles demonstrated to possess promising antioxidant properties.

\section{Discussion}

The synthesis of AgNPs has garnered the interest of the scientific community owing to their numerous applications in optronics, sensing, catalysis and pharmaceuticals. The green synthesis of NPs using plant extracts has more advantages than using microorganisms because it is a single-step method, is nonpathogenic and economic. Several plants and weeds have materialized as probable sources reducing silver nitrate in the synthesis of $\mathrm{AgNPs}^{31-33}$. The composition of organic metabolites differs among plants growing under varied climatic conditions. Consequently, there exists distinct variation in the characteristics of biologically produced $\mathrm{AgNPs}^{34-36}$.

Owing to the phenomenon of Surface Plasma Resonances (SPR), metal nanoparticles including silver exhibit absorption in the UV-Visible region of the electromagnetic spectrum ${ }^{37}$ therefore helpful in monitoring the $\mathrm{Ag}+$ reduction. A strong absorption at $\sim 415 \mathrm{~nm}$ is reflective of reduction of Ag+ ions by the BO leaf extract and ultimately the production of BO-AgNPs. Interestingly, the peak/absorption maxima provides information on the morphology of the synthesized nanoparticles. Absorption maxima at lower wavelength is indicative of smaller size NPs and broader peak/higher wavelength is typical of enlarged particle size. The absorption peak at relatively lower wavelength $(415 \mathrm{~nm})$ obtained in the present study points towards the formation of smaller size nanoparticles. AgNPs prepared with aqueous BO leaf extract show higher sensitivity of ZS showing fewer amounts of large particles and increased size of the ZS-measured particles due to aggregation. The findings are in agreement with previous studies in which a similar difference was reported ${ }^{38}$. EDX elemental analysis substantiates the occurrence of AgNPs in pellets obtained and the existence of other elements adhering on the AgNPs reflected the plant based origin of these biomolecules. The crystalline nature of AgNPs was clearly seen from the EDX pattern formed by the reduction of BO-AgNPs. A strong signal peak for silver was observed at $3 \mathrm{keV}$, confirms the formation of AgNPs. This absorption peak approximately at $3 \mathrm{keV}$ is due to surface plasmon 

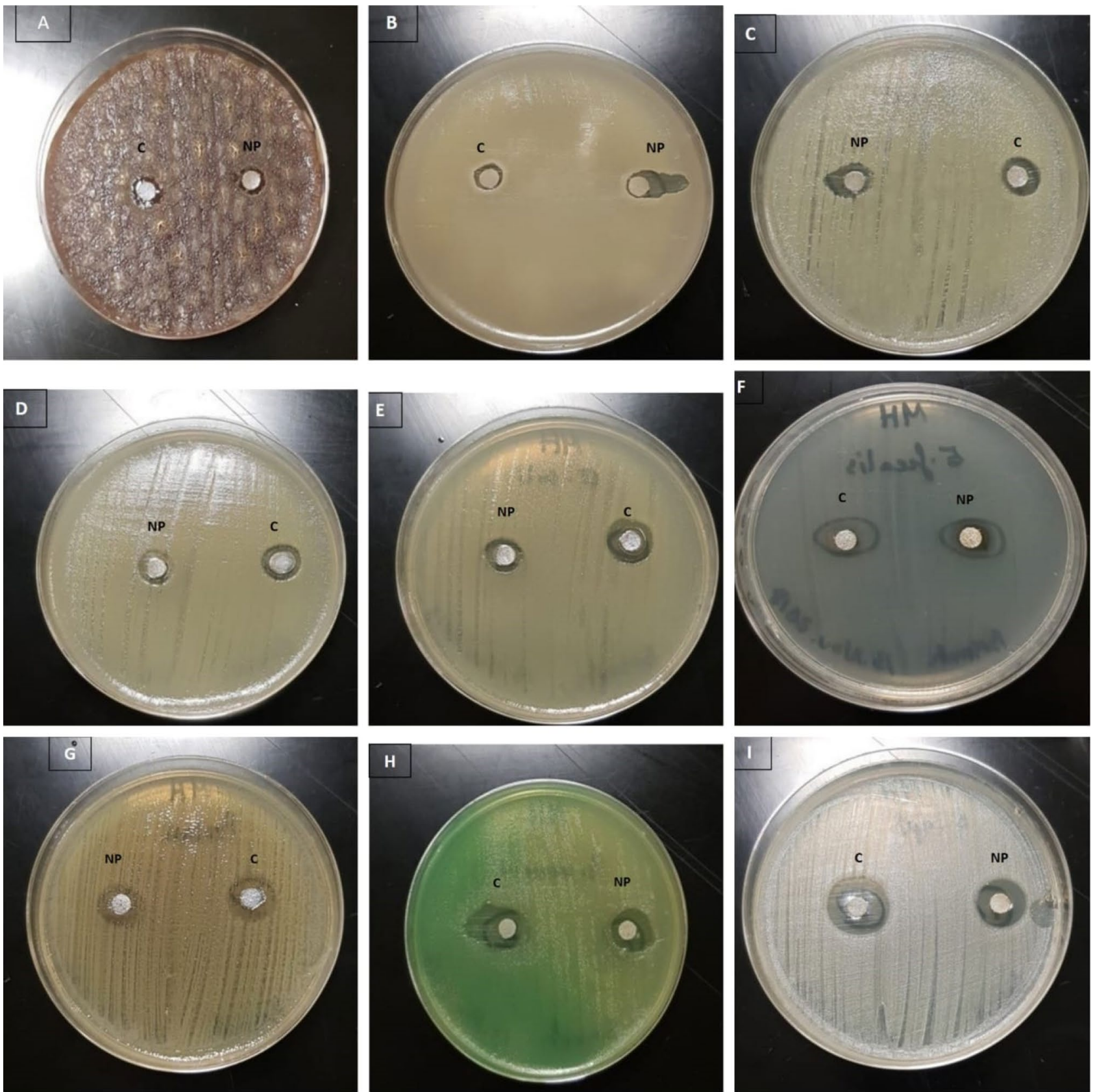

Figure 6. Antimicrobial activity of Ag nanoparticles prepared from B. oleracea against (A) Bacteroides fragilis ATCC 25285; (B) Streptococcus pneumonia ATCC 10015; (C) Staphylococcus aureus ATCC 6538; (D) Klebsiella pneumonia ATCC 10031; (E) Escherichia coli ATCC 25922; (F) Enterococcus faecalis ATCC 33186; (G) Proteus mirabilis ATCC 12453; (H) Pseudomonas aeruginosa ATCC 9027; (I) Staphylococcus epidermidis ATCC 12228.

resonance exhibited by silver ${ }^{39}$. The current observation is in line with the previous reports of Shankar et al. (2004) where a thin layer of organic material encircling the green-synthesized NPs was reported ${ }^{40}$. Furthermore, FTIR measurements were carried out in order to identify the presence of various functional groups in biomolecules responsible for the bioreduction of $\mathrm{Ag}$ and capping/stabilization of silver nanoparticles. Figure 3 shows the FTIR profile, with strong absorption peaks for $\mathrm{O}-\mathrm{H}$ groups of phenols and $\mathrm{C}-\mathrm{H}$ aromatic stretch of groups at $\sim 3500 \mathrm{~cm}^{-1}$ and $1600 \mathrm{~cm}^{-1}$ respectively.

AgNPs from B. oleracea as bactericidal agents was also investigated in the current study and results of antimicrobial activity is shown in Fig. 6. Based on the inhibition zone obtained, it was observed that the synthesized AgNPs expressed antibacterial activity in the range of 9-14 mm against Bacteroides fragilis and Staphylococcus epidermidis respectively. Highest antibacterial activity was seen against Staphylococcus epidermidis, which was the most sensitive to the AgNPs with a DIZ value of $14.33 \pm 0.57 \mathrm{~mm}$, followed by Enterococcus faecalis and Proteus mirabilis with DIZ value of $11.16 \pm 0.28 \mathrm{~mm}$ and $11.33 \pm 0.57 \mathrm{~mm}$ respectively. With respect to Gram negative bacteria, highest antibacterial activity was expressed against Pseudomonas aeruginosa $(12.0 \pm 0.20 \mathrm{~mm})$, followed by Escherichia coli $(10.0 \pm 1.0 \mathrm{~mm})$, Klebsiella pneumoniae $(10.0 \pm 0.50 \mathrm{~mm})$ and Bacteroides fragilis $(9.43 \pm 0.40 \mathrm{~mm})$. 


\begin{tabular}{|l|r|r|}
\hline \multirow{2}{*}{ Bacterial strains } & \multicolumn{2}{|l|}{ Zone of inhibition $(\mathbf{m m})$} \\
\cline { 2 - 3 } & BO-AgNP & \multicolumn{1}{l|}{ Control } \\
\hline Bacteroides fragilis & $9.43 \pm 0.40$ & $9.56 \pm 0.30$ \\
\hline Streptococcus pneumoniae & $10.33 \pm 0.57$ & $11.00 \pm 0.20$ \\
\hline Staphylococcus aureus & $10.1 \pm 0.17$ & $10.78 \pm 0.11$ \\
\hline Klebsiella pneumoniae & $10.0 \pm 0.50$ & $11.00 \pm 0.20$ \\
\hline Escherichia coli & $10.0 \pm 1.00$ & $10.8 \pm 0.50$ \\
\hline Enterococcus faecalis & $11.16 \pm 0.28$ & $11.45 \pm 0.15$ \\
\hline Proteus mirabilis & $11.33 \pm 0.57$ & $12.00 \pm 0.25$ \\
\hline Pseudomonas aeruginosa & $12.0 \pm 0.20$ & $12.5 \pm 0.15$ \\
\hline Staphylococcus epidermidis & $14.33 \pm 0.57$ & $14.59 \pm 0.67$ \\
\hline
\end{tabular}

Table 1. Antibacterial activity of biosynthesized silver nanoparticles using disc diffusion assay.

\begin{tabular}{|l|l|l|}
\hline \multirow{2}{*}{ Bacterial strains } & \multicolumn{2}{|l|}{$\begin{array}{l}\text { Minimum inhibitory } \\
\text { concentration }(\boldsymbol{\mu g} / \mathbf{m l})\end{array}$} \\
\cline { 2 - 3 } & BO-AgNPs & Positive control \\
\hline Bacteroides fragilis ATCC 25285 & 50 & 25 \\
\hline Streptococcus pneumoniae ATCC 10015 & 25 & 25 \\
\hline Staphylococcus aureus ATCC 6538 & 25 & 12.5 \\
\hline Klebsiella pneumoniae ATCC 10031 & 25 & 12.5 \\
\hline Escherichia coli ATCC 25922 & 25 & 12.5 \\
\hline Enterococcus faecalis ATCC 33186 & 12.5 & 6.25 \\
\hline Proteus mirabilis ATCC 12453 & 12.5 & 6.25 \\
\hline Pseudomonas aeruginosa ATCC 9027 & 12.5 & 3.1 \\
\hline Staphylococcus epidermidis ATCC 12228 & 6.25 & 6.25 \\
\hline
\end{tabular}

Table 2. Minimum inhibitory concentration of AgNPs synthesized by Brassica oleracea on tested bacterial strains.

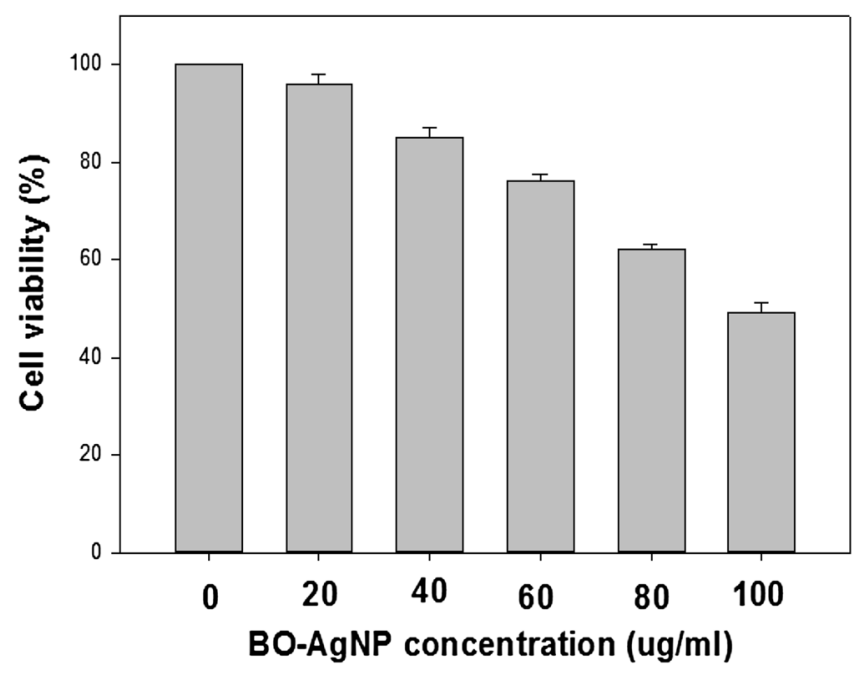

Figure 7. Effect of BO-AgNPs on cell viability of MCF-7 cell lines by MTT assay.

The observed antibacterial activity of synthesized BO-AgNPs in the current study is in accordance with previous studies $^{14,15}$. Anandalakshmi et al. (2016) observed silver nanoparticles mediating similar bactericidal action using Pedalium murex leaf extract ${ }^{41}$. Green synthesis was found to be eco-friendly and biosynthesized AgNPs possessed antibacterial activity against E. coli, Klebsiella pneumoniae, Mariniluteicoccus flavus, Pseudomonas aeruginosa, Bacillus subtilis, Bacillus. pumilus and S. aureus. Supportingly, Tamileswari (2015) observed antibacterial activity of AgNPs against pathogenic bacterial strains like K. pneumonia, B. subtilis, S. aureus and E. coli ${ }^{23}$. The results 

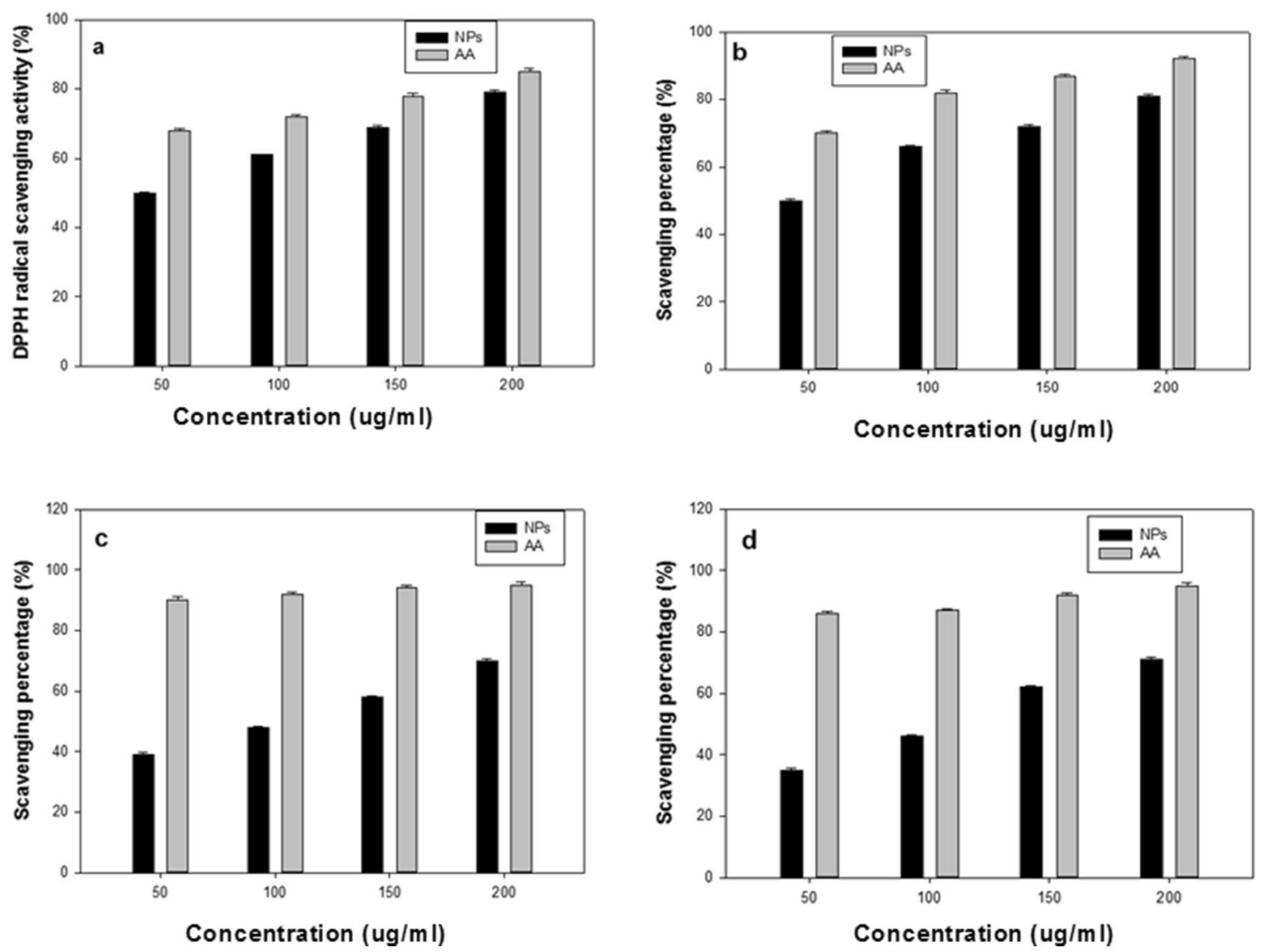

Figure 8. Free radical scavenging ability of $\mathrm{BO}-\mathrm{AgNP}_{\mathrm{S}}$ : (a) DPPH assay; (b) nitric oxide-scavenging activity; (c) superoxide activity; (d) hydroxyl-scavenging activity of BO-AgNPs with respective standards. $A A$ ascorbic acid.

obtained for Gram negative strains with maximum antibacterial activity against pseudomonas are in line with previous study by Kumar et al. (2012) $)^{42}$.

Furthermore, results obtained from Minimum inhibitory concentration (MIC) of synthesized BO-AgNPs are in accordance with antibacterial activity by agar diffusion method. The lowest MIC of $6.25 \mu \mathrm{g} / \mathrm{ml}$ was recorded for Staphylococcus epidermidis ATCC 12228, against which highest zone of inhibition (14.33 \pm 0.57 ) was observed (Table 2). Similarly, highest MIC of $50 \mu \mathrm{g} / \mathrm{ml}$ was observed against Bacteroides fragilis ATCC 25285, with lowest zone of inhibition recorded $(9.43 \pm 0.40)$. On contrary, MIC values recorded for positive control were at lower concentration, as pure AgNO3 was used. Slight variation was observed with lower MIC values recorded for Pseudomonas aeruginosa ATCC $9027(3.1 \mu \mathrm{g} / \mathrm{ml})$ and highest values recorded for Bacteroides fragilis ATCC 25285 and Streptococcus pneumoniae ATCC $10015(25 \mu \mathrm{g} / \mathrm{ml})$. The results for MIC indicate that the synthesized $\mathrm{BO}-\mathrm{AgNPs}$ are effective at a low concentration to inhibit the bacterial growth.

The growth inhibition by the AgNPs is primarily due to the formation of pores in the bacterial cell wall accompanied with changes in cell membrane permeability due to deposition of AgNPs at these sites. Several underlying mechanisms involved in antibacterial action of AgNPs have been proposed. Possibly, the disruption of the thiol group in the electron transport chain enzymes followed by the binding of the AgNPs to the cell wall and membrane of bacterial cell accounts for the inhibitory effect of these silver nanoparticles. The metallic NPs interact with bacterial cell wall through attraction between the microbial cell wall's negative charge and NPs' positive charge. Due to this interaction, the permeability function of the cell membrane changes and, hence, the bacterial integrity disrupts and causes cell death ${ }^{43}$. Additionally, the increased affinity of silver nanoparticles to elements like sulphur and phosphorus owe to the antibacterial property of these NPS. These elements are abundantly found in the bacterial cell wall and membranes. Silver nanoparticles are known to inhibit the absorption of phosphorus and altering the levels of phosphate, mannitol in the bacterial cell ${ }^{44}$. The viability of bacterial cell is reduced due to interaction of AgNPs with proteins containing sulfur in or outside of the cell membrane ${ }^{45}$. The broad-spectrum antibacterial activity of these AgNPs is due to combinatorial action ${ }^{46}$. A three way antibacterial mechanisms involves: (a) the uptake of silver ions by bacteria leading to interruption of ATP production and DNA replication, (b) AgNPs can trigger the production of free radicals generating oxidative stress, (c) AgNPs can directly damage the bacterial cell membranes leading to lysis of the cell ${ }^{47}$. The colonization of bacterial species like S. epidermidis and E. faecalis in central venous catheters poses a greater risk of catheter associated blood infections. The green-synthesized AgNPs could be manifested to minimize such catheter-associated infection, which poses higher cost for heathcare ${ }^{48-52}$. The prevalence of $S$. pneumoniae infections in ICUs can thus be minimized 
by adopting such sterilization procedures ${ }^{53}$. Furthermore, owing to its antimicrobial property, synthesized BOAgNPs can also be used in food packaging as nanosensors to detect the microbial contamination.

AgNPs also plays a key role in tumor regulation via their cytotoxic effects. Cytotoxicity of AgNPs is mediated by the action of Ag+ ions. AgNPs facilitate the formation of reactive oxygen species (ROS), superoxide synthesis following reduction of oxygen by electron from electron transport chain on the mitochondrial surface. The generated reactive oxygen species thus leads to oxidative damage of cellular contents including DNA, proteins and lipids and consequently results to cell death ${ }^{54,55}$. The cytotoxicity increased proportionately with increasing concentration of the green synthesized BO-AgNPs with maximum effect at $100 \mu \mathrm{g} / \mathrm{ml}$ suggesting their use as an alternative chemotherapeutic agent. The anticancer potential exhibited by the BO-AgNPs in the present study are in accordance with previous evidences on MCF 7 cell lines, Hep-2 cells and Hela cell lines from biosynthesized AgNPs from leaf extract of Annona squamosa, Piper longum and Morinda citrifolia respectively ${ }^{56-58}$. The anticancer property of $\mathrm{BO}-\mathrm{AgNPs}$ demonstrated by cytotoxic assay could be due to presence of compounds like sulforaphane and indole-3-carbinal, which boosts DNA repair in cells and appears to block the growth of cancer cells. Moreover, the phytonutrients and antioxidants play a chemo-protective role against oxidative stress-related diseases such as cancer.

Human body is under vulnerable attack by the free radicals causing cellular damage, which is generally being neutralized by the antioxidant molecules. Majority of antioxidants are known to decelerate the progression of chronic diseases. Cellular oxidation which is crucial for the growth of the cell is associated with some adverse effects due to the generation of free radicles and reactive oxygen species. These free radicals in surplus amounts lead to devastating effect on the protective antioxidant enzymes like superoxide dismutase, catalase and peroxidase resulting in cellular damage by oxidizing vital biomolecules, subsequently leading to apoptosis/cell death ${ }^{59}$. The antioxidant efficiency of BO-AgNPs tested against various free radicals yielded intriguing results in this study. Presence of phytochemicals like flavonoids with several hydroxyl groups and phenolic functional groups on the surface as capping agents on these nanoparticles may account for the observed antioxidant capacity. The observed antibacterial, antioxidant and cytotoxic activity of the silver nanoparticles evidenced in the present study are in accordance with previous studies ${ }^{60,61}$.

\section{Conclusion}

The synthesized silver nanoparticles from Brassica oleracea (BO) by green chemistry demonstrated an enhanced antibacterial, anticancer, and antioxidant activity. The applicability of nanoparticles is extendable to various fields like environment, biomedical, and electrochemistry due to lack of toxic reagents in the process of green synthesis. In conclusion, synthesis of Ag-NPs by green process has emerged as promising tools in extension of the plant mediated nanocarriers in the field of tumor diagnosis, drug delivery systems and radiological imaging.

\section{Methodology}

Processing of $\mathrm{BO}$ leaves. Fresh green leaves of Brassica oleracea (BO) had been washed with double-distilled water and subsequently air-dried at $20^{\circ} \mathrm{C}$. Later these leaves (around twenty grams) were boiled in $250 \mathrm{ml}$ of ultrapure water for $20 \mathrm{~min}$ to prepare the leaf extract, and cooled. The prepared BO-AgNPs were stored until further investigation at $4^{\circ} \mathrm{C}$.

Preparation of silver nanoparticles (green synthesis). Silver nitrate $\left(\mathrm{AgNO}_{3}\right)$ from Sigma-Aldrich with $\geq 99.5 \%$ purity was utilized. $5 \mathrm{ml}$ of the leaf extract was collected for reduction of $1 \mathrm{mM} \mathrm{Ag- \textrm {NO } _ { 3 }}(50 \mathrm{ml})$ aqueous solution at ambient temperature for $10 \mathrm{~min}$, resulting in a brownish yellow solution, thus demonstrating the development of AgNPs. UV-Vis Spectrophotometer was used to monitor the synthesized nanoparticles for $5 \mathrm{~h}$.

Characterization of synthesized nanoparticles. The following protocols have been used to characterize the synthesized leaf extract AgNPs.

Detection of BO-AgNPs by UV-Vis spectrophotometry. UV-Vis spectrophotometer (LIUV-310, Lambda Scientific, Australia) was employed to measure the Surface Plasmon Resonance (SPR), resulting due to production of silver nanoparticles typically from direct reduction of silver nitrate by BO extract following method of Shanker et al. $(2005)^{59}$. The analysis was performed in quartz cuvettes using distilled water as a reference solvent. Ag-NP samples for UV-Vis analysis were diluted in 1:4 ratio; prepared by diluting $2 \mathrm{ml}$ of Ag-NP solution in $8 \mathrm{ml}$ of distilled water. Absorption spectra was obtained by sampling approximately one milliliter of the suspension at different time intervals $(1,3$, and $5 \mathrm{~h})$ to track the completion of bioreduction of $\mathrm{Ag}+$ ions.

Particle size and zeta potential (ZP) analysis. The Zetasizer (ZS) Nano Series ZS (model number ZEN3600) determined the hydrodynamic size and zeta potential of the AgNPs following method of Erdogan et al. $(2019)^{62}$. The red laser (wavelength- $633 \mathrm{~nm}$ ) is incidented at an scattering angle of $173^{\circ}$ in a medium with viscosity of 0.887 milli Pascals at $25^{\circ} \mathrm{C}$ to analyze the size of the particle. The zeta potential value facilitates the understanding of interparticle forces of interaction. The ZP value affects the constancy of colloidal system. Low-density, small particles in suspension with high $+/-$ zeta potentials deter each other.

Energy dispersive X-ray (EDX) spectroscopic analysis. JEOL JEM 2100 high-resolution was used for EDX analysis of BO-AgNPs. The presence of elemental silver was validated through EDX with detection of other elements in the particle. Energy dispersive analysis X-ray spectrometer works utilizing the properties of photon; unit of 
light. The energy of single photon in the X-ray region produces a measurable pulse X-ray. X-ray, besides processing electronics are detected by semiconductor material for spectral analysis. The EDX observations were recorded coupled with $\mathrm{SEM}^{62}$.

Evaluation of antibacterial activity. The bactericidal property of the synthesized BO-AgNPs were investigated on selected bacterial strains procured from American Type Culture Collection Center (ATCC). Both Grampositive and Gram-negative strains including Bacteroides fragilis ATCC 25285, Pseudomonas aeruginosa ATCC 9027, Staphylococcus aureus ATCC 6538, Enterococcus faecalis ATCC 33186, Streptococcus pneumoniae ATCC 10015, Proteus mirabilis ATCC 12453, Klebsiella pneumoniae ATCC 10031, Escherichia coli ATCC 25922, and Staphylococcus epidermidis ATCC 12228 were tested. Inoculum was prepared as per CLSI M02-A12 ${ }^{63}$. For preparation of inoculum, isolated colonies of each bacterial culture were selected from 18-24 h incubated agar plates and inoculated in tryptone soya broth (Oxoid, UK) to make a suspension. The turbidity of the suspension was adjusted to achieve a CFU of $1.0-2.0 \times 10^{8} \mathrm{CFU} / \mathrm{ml}$ (CLSI) by UV-Visible Spectrophotometer (UV 1800, Shimatzu, Switzerland) at $600 \mathrm{~nm} .0 .1 \mathrm{ml}$ of each bacterial culture suspension was inoculated on Mueller Hinton agar (Oxoid, UK) plates and evenly spread with a sterile spreader. Sterile paper disc of $6 \mathrm{~mm}$ diameter containing $25 \mu \mathrm{g} / \mathrm{ml}$ silver nanoparticles along with $\mathrm{AgNO}_{3}(30 \mu \mathrm{g} / \mathrm{ml})$ containing discs was placed in each plate as control. Antibacterial activity was tested by standard Kirby-Bauer Method ${ }^{64}$, Mueller Hinton agar was employed and Petri dishes $(90 \mathrm{~mm}$ ) containing $18 \mathrm{ml}$ of Mueller Hinton agar were seeded with $100 \mu$ inoculum (approximately $10^{8} \mathrm{CFU} / \mathrm{ml}$ ) of each bacterial strain in Mueller Hinton broth.

The inoculum of each bacterial culture were evenly spread on petri dishes and discs previously saturated were placed on petri dishes with culture. All petri dishes were kept at $37^{\circ} \mathrm{C}$ for $18-24 \mathrm{~h}$ for incubation and diameter of zone of inhibition (DIZ) was calculated. The experiment was run in triplicate and DIZ value were reported as mean $\pm \mathrm{SD}$ values.

Determination of minimum inhibitory concentration (MIC). MIC of the synthesized NPs was determined by Macrodilution method in sterile test tubes as per CLSI $07-08^{65}$. Serial dilutions of synthesized NPs were made from a concentration of $1 \mathrm{mg} / \mathrm{ml}$ to get a concentration of $100 \mu \mathrm{g} / \mathrm{ml}$ to $50,25,12.5,6.25,3.1,1.5 \mathrm{and} 0.78 \mu \mathrm{g} /$ $\mathrm{ml}$. Standard AgNO3 was also tested for determination of MIC in the same range of concentration for comparative analysis. The inoculum for test strains containing $5 \times 10^{5} \mathrm{CFU} / \mathrm{ml}$ was prepared in a similar manner as for antibacterial activity testing.

Cytotoxicity assay. Eagle minimum essential medium (EMEM) containing 10\% FBS was used to culture Human breast cancer cell lines (MCF-7). The following conditions were maintained in incubator- $95 \%$ air, $100 \%$ relative humidity, $5 \% \mathrm{CO}_{2}$ and temperature $37^{\circ} \mathrm{C}$. To obtain a final density of $1 \times 10^{5}$ cells $/ \mathrm{ml}$, viable cells were enumerated using a hemocytometer, with $5 \%$ FBS as diluents. 96 well polystyrene-coated plate (flat bottomed) was overlaid with MCF-7 cells (in growth phase) and incubated for cell attachment. AgNPs at varying concentrations: $0,20,40,60,80,100 \mu \mathrm{gm} / \mathrm{ml}$ was added to the seeded cell lines and treated for $48 \mathrm{~h}$. Phosphate buffered saline (PBS) containing MTT (3-(4,5-Dimethylthiazol-2-yl)-2,5-diphenyltetrazolium bromide $5 \mathrm{mg} / \mathrm{ml}$ ) reagent was added after $24 \mathrm{~h}$ and incubated further for $3 \mathrm{~h}$ at $37^{\circ} \mathrm{C}$. The medium served as control. Post incubation absorbance was read in micro plate reader at $570 \mathrm{~nm}$. The cell viability percentage was then determined with respect to control ${ }^{66}$.

Evaluation of antioxidant assay. DPPH assay. The antioxidant property of synthesized BO-AgNPs was determined by DPPH-radical scavenging assay. BO-AgNPs prepared at varying concentration-50, 100, 150 and $200 \mu \mathrm{g} / \mathrm{ml}$ were thoroughly agitated and mixed with $0.1 \mathrm{mM} \mathrm{DPPH}$. The solution was incubated in dark for $15 \mathrm{~min}$. The decrease in the concentrations of DPPH was monitored by measuring absorbance at $517 \mathrm{~nm}^{67}$. Later, the antioxidant capacity of BO-AgNPs calculated using ascorbic acid as the standard. The DPPH scavenging ability was expressed in $\%$ as follows.

$$
\begin{aligned}
\mathrm{DPPH} \text { scavenging assay percentage }= & \text { Control absorbance } \\
& -(\text { Sample absorbance }- \text { blank absorbance }) \\
& \text { / control absorbance } \times 100
\end{aligned}
$$

Nitric oxide radical-scavenging assay. For determination of nitric oxide scavenging activity, BO-AgNPs at different concentrations were mixed with $2 \mathrm{ml} \mathrm{Fe}$-NPs and incubated at room temperature for $150 \mathrm{~min}$. Following incubation, around $0.5 \mathrm{ml}$ aliquot of the incubated mixture was mixed with $1 \mathrm{ml}$ of sulfanilic acid $(0.33 \%$ sulfanilamide in $20 \%$ acetic acid) and incubated further for $5 \mathrm{~min}$. Subsequently, $0.1 \%$ naphthyl ethylenediamine dihydrochloride was added to the above reaction solution and incubated for additional $30 \mathrm{~min}$ at the ambient temperature and the absorbance read at $546 \mathrm{~nm}^{68}$. The scavenging percentage was calculated as follows:

$$
\% \text { scavenging/reduction }=\left(\mathrm{T}_{0}-\mathrm{T}\right)=\mathrm{T}_{0} \times 100 ;
$$

where $\mathrm{T}_{0}$-absorbance of the control, $\mathrm{T}$-absorbance of the test sample.

Superoxide anion radical-scavenging assay. Concisely, about $1 \mathrm{ml}$ reaction mixture containing $100 \mathrm{mM}$ phosphate buffer ( $\mathrm{pH} 7.4$ ), $468 \mu \mathrm{M}$ NADH, $156 \mu \mathrm{M}$ NBT and $60 \mu \mathrm{M}$ PMS was prepared and mixed with varying concentrations of nanoparticles ranging from 50-200 $\mu \mathrm{g}$. The reaction mixture was further incubated at room 
temperature for $5 \mathrm{~min}$. Superoxide anion radical-scavenging assay was determined by measuring the formation of the purple formazan (nitroblue tetrazolium) detectable at $560 \mathrm{~nm}$ in spectrophotometer. The product is formed after detoxification of superoxide radicals generated from NAD (nicotinamide adenine dinucleotide) by $\mathrm{BO}-\mathrm{AgNPs}^{69}$.

Hydroxyl radical-scavenging assay. Briefly, a reaction mixture volume of about $3 \mathrm{ml}$ was prepared containing $1 \mathrm{ml}$ each of $9 \mathrm{mM}$ salicylic acid, $9 \mathrm{mM}$ ferrous sulfate and hydrogen peroxide and mixed following addition of $1 \mathrm{ml}$ of synthesized BO-AgNPs. After incubation, for $60 \mathrm{~min}$ at $37^{\circ} \mathrm{C}$ in boiling water bath the absorbance of the resulting solution was measured at $510 \mathrm{~nm}$. Experiment was repeated running negative control and the percentage of hydroxyl radical scavenging activity for test samples was calculated ${ }^{70}$.

Statistical analysis. Statistical analysis was performed with one-way analysis of variance (ANOVA). For statistical analyses the SPSS 17.0 software was used. Three replications for each of the experiments and assays were conducted $(n=3)$. A mean of the three values reported in each case.

Received: 6 July 2020; Accepted: 23 September 2020

Published online: 29 October 2020

\section{References}

1. Hardman, R. Toxicologic review of quantum dots: toxicity depends on physicochemical and environmental factors. Environ. Health Perspect. 114, 165-172 (2006).

2. Curtis, J., Greenberg, M., Kester, J., Phillips, S. \& Krieger, G. Nanotechnology and nanotoxicology: a primer for clinicians. Toxicol. Rev. 25, 245-260 (2006).

3. Lewinski, N., Colvin, V. \& Drezek, R. Cytotoxicity of nanoparticles. Small 4, 26-49 (2008).

4. Huang, J. et al. Biosynthesis of silver and gold nanoparticles by novel sundried Cinnamomumcamphora leaf. Nanotechnology 18, 105104 (2007).

5. Leela, A. \& Vivekanandan, M. Tapping the unexploited plant resources for the synthesis of silver nanoparticles. Afr. J. Biotechnol. 17, 3162-3165 (2008).

6. Kowshik, M. et al. Extracellular synthesis of silver nanoparticles by a silver-tolerant yeast strain MKY3. Nanotechnology 14, 95-100 (2003).

7. Si, S. \& Mandal, T. K. Tryptophan-based peptides to synthesize gold and silver nanoparticles: a mechanistic and kinetic study. Chemistry 13, 3160-3168 (2007).

8. Kim, J. et al. Peptide-mediated shape-and size-tunable synthesis of gold nanostructures. Acta Biomater. 6, 2681-2689 (2010).

9. Malik, P., Shankar, R., Malik, V., Sharma, N. \& Mukherjee, T. K. Green chemistry based benign routes for nanoparticle synthesis. J. Nanopart. 302429, 1 (2014).

10. Kowshik, M. et al. Microbial synthesis of semiconductor CdS nanoparticles, their characterization, and their use in the fabrication of an ideal diode. Biotechnol. Bioeng. 78, 583-588 (2002).

11. Klaus-Joerger, T., Joerger, R., Olsson, E. \& Granqvist, C. G. Bacteria as workers in the living factory: metal-accumulating bacteria and their potential for materials science. Trends Biotechnol. 19, 15-20 (2001).

12. Govindaraju, K., Tamilselvan, S., Kiruthiga, V. \& Singaravelu, G. Biogenic silver nanoparticles by Solanum torvum and their promising antimicrobial activity. J. Biopesticides 3, 394-399 (2010).

13. Mandal, D., Bolander, M. E., Mukhopadhyay, D., Sarkar, G. \& Mukherjee, P. The use of microorganisms for the formation of metal nanoparticles and their application. Appl. Microbiol. Biotechnol. 69, 485-492 (2006).

14. Hassan, S. E. et al. Endophytic actinomycetes Streptomyces spp. mediated biosynthesis of copper oxide nanoparticles as a promising tool for biotechnological applications. J. Biol. Inorg. Chem. 24(3), 377-393 (2019).

15. Salem, S. S. et al. Antibacterial, cytotoxicity and larvicidal activity of green synthesized selenium nanoparticles using Penicillium corylophilum. J. Clust. Sci. https://doi.org/10.1007/s10876-020-01794-8 (2020).

16. Roy, N. \& Barik, A. Green synthesis of silver nanoparticles from the unexploited weed resources. Int. J. Nanotechnol. 4, 95 (2010).

17. Sivakumar, A. S. et al. Interaction of silver and gold nanoparticles in mammalian cancer: as real topical bullet for wound healing-a comparative study. In Vitro Cell Dev. Biol. Anim. 53, 632-645 (2017).

18. Zhang, J. \& Li, S. Sensors for detection of Cr(VI) in water: a review. Int. J. Environ. Anal. Chem.1 (2019).

19. Vorobyova, V., Vasyliev, G. \& Skiba, M. Eco-friendly, "green" synthesis of silver nanoparticles with the black currant pomace extract and its antibacterial, electrochemical, and antioxidant activity. Appl. Nanosci. https://doi.org/10.1007/s13204-020-01369-z (2020).

20. Skiba, M.I., Vorobyova, V.I., Pivovarov, O.A., \& Makarshenko, N.P. Green synthesis of silver nanoparticles in the presence of polysaccharide: optimization and characterization. J. Nanomater. Article ID 3051308 (2020)

21. Poulose, S., Panda, T., Nair, P. P. \& Théodore, T. Biosynthesis of silver nanoparticles. J. Nanosci. Nanotechnol. 14, 2038-2049 (2014).

22. Russo, M. et al. Photosynthesized silver-polyaminocyclodextrin nanocomposites as promising antibacterial agents with improved activity. RSC Adv. 6, 40090-40099 (2016).

23. Tamileswari, R., Haniff Nisha, M. \& Jesurani, S. Sr. Green synthesis of silver nanoparticles using Brassicaoleracea (cauliflower) and Brassicaoleracea capitata (cabbage) and the analysis of antimicrobial activity. Int. J. Eng. Res. Technol. 4, 1071 (2015).

24. Singh, A., Sharma, B. \& Deswal, R. Green silver nanoparticles from novel Brassicaceae cultivars with enhanced antimicrobial potential than earlier reported Brassicaceae members. J. Trace Elem. Med. Biol. 47, 1-11 (2018).

25. Molnar, A. et al. Nitro-oxidative signalling induced by chemically synthetized zinc oxide nanoparticles (ZnO NPs) in Brassica species. Chemosphere 251, 126419 (2020).

26. Prakash, S. \& Deswal, R. Analysis of temporally evolved nanoparticle-protein corona highlighted the potential ability of gold nanoparticles to stably interact with proteins and influence the major biochemical pathways in Brassicajuncea. Plant Physiol. Biochem. 146, 143-156 (2020).

27. Chen, Y. et al. Erratum to: Observation of yttrium oxide nanoparticles in cabbage (Brassicaoleracea) through dual energy K-edge subtraction imaging. J. Nanobiotechnol. 14,31 (2016).

28. Chen, Y. et al. Observation of yttrium oxide nanoparticles in cabbage (Brassicaoleracea) through dual energy K-edge subtraction imaging. J. Nanobiotechnol. 14, 23 (2016).

29. Kuppusamy, P. et al. Intracellular biosynthesis of Au and Ag nanoparticles using ethanolic extract of Brassicaoleracea L. and studies on their physicochemical and biological properties. J. Environ. Sci. (China) 29, 151-157 (2015).

30. Singh, A., Singh, N. B., Hussain, I. \& Singh, H. Effect of biologically synthesized copper oxide nanoparticles on metabolism and antioxidant activity to the crop plants Solanumlycopersicum and Brassicaoleracea var. botrytis. J. Biotechnol. 262, 11-27 (2017).

31. Bouqellah, N. A., Mohamed, M. M. \& Ibrahim, Y. Synthesis of eco-friendly silver nanoparticles using Allium sp. and their antimicrobial potential on selected vaginal bacteria. Saudi J. Biol. Sci. 26, 1789-1794 (2019). 
32. Moodley, J. S., Krishna, S. B., Pillay, K. \& Govender, P. Green synthesis of silver NPs from Moringaoleifera leaf extracts and its antimicrobial potential. Adv. Nat. Sci. Nanosci. Nanotechnol. 9, 015011 (2018).

33. Yu, C. et al. Green biosynthesis of silver NPs using Eriobotryajaponica (Thunb.) leaf extract for reductive catalysis. Materials 12, 189 (2019).

34. Mahdi, S., Taghdiri, M., Makari, V. \& Rahimi-Nasrabadi, M. Procedure optimization for green synthesis of silver nanoparticles by aqueous extract of Eucalyptusoleosa. Spectrochim. Acta Part A 136, 1249-1254 (2015).

35. Kummara, S., Patil, M. B. \& Uria, T. Synthesis, characterization, biocompatible and anticancer activity of green and chemically synthesized silver nanoparticles-a comparative study. Biomed. Pharmacother. 84, 10-21 (2016).

36. Sathish Kumar, G. et al. Phytosynthesis of silver nanoscale particles using Morindacitrifolia L. and its inhibitory activity against human pathogens. Colloids Surf. B Biointerfaces 95, 235-240 (2012).

37. Sampaio, B. L., Edrada-Ebel, R. \& Da Costa, F. B. Effect of the environment on the secondary metabolic profile of Tithonia diversifolia: a model for environmental metabolomics of plants. Sci. Rep. 6, 29265 (2016).

38. Baalousha, M. \& Lead, J. R. Size fractionation and characterization of natural aquatic colloids and nanoparticles. Sci. Total Environ. 386, 93-102 (2007).

39. Bar, H. et al. Green synthesis of silver nanoparticles using latex of Jatrophacurcas. Colloids Surf A. 339, 134-139 (2009).

40. Shankar, S. S., Rai, A., Ahmad, A. \& Sastry, M. Rapid synthesis of Au, Ag, and bimetallic Au core Ag shell nanoparticles using neem (Azadirachtaindica) leaf broth. J. Colloid Interface Sci. 275, 496-502 (2004).

41. Anandalakshmi, K., Venugopal, J. \& Ramasamy, V. Characterization of silver nanoparticles by green synthesis method using Pedalium murex leaf extract and their antibacterial activity. Appl. Nanosci. 6, 399 (2016).

42. Kumar, P. et al. Synthesis of silver nanoparticles from Sargassum tenerrimum and screening phytochemicals for its antibacterial activity. Nano. Biomed. Eng. 4, 12-16 (2012).

43. Yamanaka, M., Hara, K. \& Kudo, J. Bactericidal action of silver ion solution on Escherichiacoli, studied by energy-filtering transmission electron microscopy and proteomic analysis. Appl. Environ. Microbiol. 71, 7589-7593 (2005).

44. Hamouda, T. \& Baker, J. Jr. Antimicrobial mechanism of action of surfactant lipid preparations in enteric Gram-negative bacilli. J. Appl. Microbiol. 89, 397-403 (2000).

45. Tamboli, D. P. \& Lee, D. S. Mechanistic antimicrobial approach of extracellularly synthesized silver nanoparticles against Gram positive and Gram negative bacteria. J. Hazard Mater. 260, 878-884 (2013).

46. Jones, M. C. \& Hoek, E. M. A review of the antibacterial effects of silver nanomaterials and potential implications for human health and the environment. J. Nanopart. Res. 12, 1531-1551 (2010).

47. Salem, S. S. \& Fouda, A. Green synthesis of metallic nanoparticles and their prospective biotechnological applications: an overview. Biol. Trace Elem. Res. https://doi.org/10.1007/s12011-020-02138-3 (2020).

48. Masoud, E. A., Al-Hajry, A. M. \& Al-Marrani, A. Antibacterial activity of silver nanoparticles synthesized by Sidr (Ziziphusspina christi) leaf extract against pathogenic bacteria. Int. J. Curr. Microbiol. Appl. Sci. 5, 226 (2016).

49. Mermel, L. A. et al. Guidelines for the management of intravascular catheter-related infections. Clin. Infect. Dis. 32, 1249-1272 (2001).

50. Dimick, J. B. et al. Increased resource use associated with catheter-related bloodstream infection in the surgical intensive care unit. Arch. Surg. 136, 229-234 (2001).

51. Francolini, I. \& Donelli, G. Prevention and control of biofilm-based medical device-related infections. FEMS Immunol. Med. Microbiol. 59, 227-238 (2010).

52. Padmavathy, K., Praveen, S., Madhavan, R., Krithika, N. \& Kiruthiga, A. Clinico-microbiological investigation of catheter associated urinary tract infection by Enterococcusfaecalis: van Agenotype. J. Clin. Diagn. Res. 9, 5 (2015).

53. Paling, F. P. et al. Staphylococcusaureus colonization at ICU admission as a risk factor for developing S. aureus ICU pneumonia. Clin. Microbiol. Infect. 23, 1-49 (2015).

54. Borchert, H. Determination of nanocrystal sizes: a comparison of TEM, SAXS, and XRD studies of high lymonodisperse CoPt3 particles. Langmuir 21, 1931-1936 (2005).

55. Arunachalam, K. D., Arun, L. B., Annamalai, S. K. \& Arunachalam, A. M. Potential anticancer properties of bioactive compounds of Gymnemasylvestre and its biofunctionalized silver nanoparticle. Int. J. Nanomed. 10, 31-41 (2015).

56. Vivek, R. et al. Green biosynthesis of silver nanoparticles from Annonasquamosa leaf extract and its in vitro cytotoxic effect on MCF-7 cells. Process. Biochem. 47, 2405 (2012).

57. Jacob, S. J. P., Finub, J. S. \& Narayanan, A. Synthesis of silver nanoparticles using Piperlongum leaf extracts and its cytotoxic activity against Hep-2 cell line. Colloids Surf. B Biointerfaces 91, 212-214 (2012).

58. Suman, T. Y., Rajasree, S. R., Kanchana, A. \& Elizabeth, S. B. Biosynthesis, characterization and cytotoxic effect of plant mediated silver nanoparticles using Morindacitrifolia root extract. Colloids Surf. B Biointerfaces 106, 74-78 (2013).

59. Shankar, S. S., Rai, A., Ahmad, A. \& Sastry, M. Controlling the optical properties of lemongrass extract synthesized gold nanotriangles and potential application in infrared-absorbing optical coatings. Chem. Mater. 17, 566-572 (2005).

60. Alsharif, S. M. et al. Multifunctional properties of spherical silver nanoparticles fabricated by different microbial taxa. Heliyon https://doi.org/10.1016/j.heliyon.2020.e03943 (2020).

61. Fouda, A. et al. Antimicrobial, antioxidant and larvicidal activities of spherical silver nanoparticles synthesized by endophytic Streptomyces spp. Biol. Trace Elem. Res. 195, 707-724 (2020).

62. Erdogan, O. et al. Green synthesis of silver nanoparticles via Cynarascolymus leaf extracts: The characterization, anticancer potential with photodynamic therapy in MCF7 cells. PLoS ONE 14(6), e0216496 (2019).

63. Clinical Laboratory Standard Institute M02-A12. Performance Standards for Antimicrobial Disk Susceptibility Tests; Approved Standard $-12^{\text {th }}$ Edition, CLSI, Wayne, Pennsylvania, vol. 35. no. 1 (2015).

64. Bauer, A. W., Kirby, W. M., Sherris, J. C. \& Turck, M. Antibiotic susceptibility testing by a standardized single disk method. Am. J. Clin. Pathol. 45, 493-496 (1966).

65. Clinical Laboratory Standard Institute M07-A8. Methods for Dilution Antimicrobial Susceptibility Tests for Bacteria That Grow Aerobically; Approved Standard-8th Edition, CLSI, Wayne, Pennsylvania, vol. 29, no. 2 (2009).

66. Denizot, F. \& Lang, R. Rapid colorimetric assay for cell growth and survival. Modifications to the tetrazolium dye procedure giving improved sensitivity and reliability. J. Immunol. Methods 89, 271-277 (1986).

67. Souza, B. W. et al. Chemical characterization and antioxidant activity of sulfated polysaccharide from the red seaweed Gracilariabirdiae. Food Hydrocoll. 27(2), 287-292 (2012).

68. Patel Rajesh, M. \& Patel Natvar, J. In vitro antioxidant activity of coumarin compounds by DPPH, super oxide and nitric oxide free radical scavenging methods. J. Adv. Pharm. Educ. Res. 1, 52-68 (2011).

69. Nishikimi, M., Rao, N. A. \& Yagi, K. The occurrence of superoxide anion in the reaction of reduced phenazine methosulfate and molecular oxygen. Biochem. Biophys. Res. Commun. 46(2), 849-854 (1972).

70. Smirnoff, N. \& Cumbes, Q. J. Hydroxyl radical scavenging activity of compatible solutes. Phytochemistry 28(4), 1057-1060 (1989).

\section{Acknowledgements}

The authors are thankful to Research Support and Services Unit, King Saud University for technical support. The authors also thank Ms. Jocelyn Palao for her help in the preparation of samples. 


\section{Author contributions}

Conceptualisation, S.A.; Data curation, H.T. and M.A.; Methodology, N.S.M.A., B.A., M.N.A. and N.B.; Project administration, S.A.; Software, N.B.; Supervision, S.A.; Validation, M.A. and S.A.M.; Writing-original draft, S.A. and M.N.A.; Writing-review and editing, S.A., H.T., M.A. and R.A.

\section{Funding}

This work was supported by Deanship of Scientific Research, King Saud University through the Undergraduate Student Research Support Program (Grant No. URSP-4-18-41).

\section{Competing interests}

The authors declare no competing interests.

\section{Additional information}

Correspondence and requests for materials should be addressed to S.A.

Reprints and permissions information is available at www.nature.com/reprints.

Publisher's note Springer Nature remains neutral with regard to jurisdictional claims in published maps and institutional affiliations.

(1) Open Access This article is licensed under a Creative Commons Attribution 4.0 International License, which permits use, sharing, adaptation, distribution and reproduction in any medium or format, as long as you give appropriate credit to the original author(s) and the source, provide a link to the Creative Commons licence, and indicate if changes were made. The images or other third party material in this article are included in the article's Creative Commons licence, unless indicated otherwise in a credit line to the material. If material is not included in the article's Creative Commons licence and your intended use is not permitted by statutory regulation or exceeds the permitted use, you will need to obtain permission directly from the copyright holder. To view a copy of this licence, visit http://creativecommons.org/licenses/by/4.0/.

(c) The Author(s) 2020 